\title{
Evaluation of Corrosion Resistance of Nickel-based Alloy EP718 for use in Hydrogen Sulphide Containing Environment
}

\author{
Ekaterina Alekseeva ${ }^{1,}{ }^{*}$, Lyudmila Galata ${ }^{1}$, Andrey Lapechenkov ${ }^{1}$, Mark Kovalev ${ }^{1}$ \\ ${ }^{1}$ Peter the Great Saint Petersburg Polytechnic University, 195427, Polytechnicheskaya 29, Saint Petersburg, Russia
}

\begin{abstract}
Nickel-based alloys cover a wide range of oil and gas applications. Alloy EP718 is used as an analogue of alloy 718. The corrosion resistance of EP718 has been determined in severe environmental conditions of NACE level VI over 3 months $\left(175^{\circ} \mathrm{C}, \mathrm{P}_{\mathrm{CO} 2}=3.5 \mathrm{MPa}, \mathrm{P}_{\mathrm{H} 2 \mathrm{~S}}=3.5 \mathrm{MPa}, \mathrm{pH} 3.5,20 \% \mathrm{NaCl}\right)$. The effects of heat treatment on the corrosion rate were studied. The results indicate that the corrosion rate of EP718 in a simulated environment is less than $0.01 \mathrm{~mm}$ per year. Stress corrosion cracking could be observed in low quality production and incorrect heat treatment.
\end{abstract}

\section{Introduction}

Dispersion hardened nickel-based alloys have a wide range of oil and gas applications. They are mostly used for manufacturing costly complex equipment for drilling, and finishing components (SSV, rebar, production packers and others) [1-4], which are used in aggressive conditions, in environments with high concentrations of chlorides, carbon dioxide, hydrogen sulfide, at temperatures up to $250^{\circ} \mathrm{C}$ [5]. The choice of material for these conditions is of great importance and should provide reliable work in operation conditions.

Nickel dispersion hardened alloys have a high corrosion resistance and high strength, nevertheless, for safe usage, it is recommended to confirm their resistance in conditions approximate to real-life, since damage to production technology and a suboptimal heat treatment can lead to various damage, particularly, sulfide stress corrosion cracking (SSCC) [11].

Qualifying nickel alloys in accordance with NACE MR0175/ISO 15156 is usually carried out by conducting tests for corrosion cracking under an applied load in a test environment, imitating real-life conditions [9]: temperature, partial pressure of gases (hydrogen sulfide and carbon dioxide). One of the main factors determining the kinetics of SSCC is the concentration of $\mathrm{H}_{2} \mathrm{~S}$. In the paper [7] it is shown that increasing the partial pressure of hydrogen sulfide $\left(\mathrm{P}_{\mathrm{H} 2 \mathrm{~S}}\right)$ from 0 to 0.2 $\mathrm{MPa}$ speeds up the growth of cracks, which is also evidenced by microscope data [6]. The usual test period is one month. However, the test time for nickel alloys is 3 months [10]. There are also suggestions to extend the testing period for nickel alloys.

There are many works which describe the test results for corrosion resistance in conditions approximate to real-life. However, data on the corrosion resistance of alloy EP718, close in composition to the alloy Inconel $718[2,3,4,5,11,13]$, is missing.
The goal of this paper is to research the corrosion resistance of alloy EP718, including assessing the corrosion rate resistance to corrosion stress cracking of the nickel alloy EP718 in conditions approximate to reallife. This work also assesses the impact of heat treatment on the corrosive properties of the studied alloy.

\section{Experimental procedure}

\subsection{Materials}

The chemical composition and mechanical properties of the alloy EP718 are presented in Table 1. The production technology for the alloy included double-vacuum remelting, casting, press draft and forging into a $110 \mathrm{~mm}$ bar. Heat treatment was carried out in a lab furnace. Heat treatment mode: quenching at a temperature of $980^{\circ} \mathrm{C}$, $1030^{\circ} \mathrm{C}, 1080^{\circ} \mathrm{C}, 1130^{\circ} \mathrm{C}$, intermediate aging over 5 hours and final aging over 16 hours.

The rate of corrosion was evaluated after four heat treatment modes. The difference between these modes was that the quenching temperature and time of holding the samples changed. The aging stages remained the same everywhere.

Table 1. Chemical compositions (wt. \%) and mechanical properties of EP718.

\begin{tabular}{|c|c|c|c|c|c|c|}
\hline $\mathrm{C}$ & $\mathrm{Ni}$ & $\mathrm{Cr}$ & $\mathrm{Mo}$ & $\mathrm{Ti}$ & $\mathrm{Al}$ & $\begin{array}{c}\text { Actual yield } \\
\text { strength, MPa }\end{array}$ \\
\hline 0.063 & 47.0 & 14.0 & 4.1 & 0.8 & 0.97 & 800 \\
\hline
\end{tabular}

\subsection{Corrosion properties}

The corrosion resistance was assessed by determining the rate of corrosion with gravimetric autoclave testing

\footnotetext{
* Corresponding author: alekseeva el@spbstu.ru
} 
and tests for resistance to sulfide stress corrosion cracking (SSCC).

Corrosion testing (pitting corrosion and SSC) was performed in the environment level VI MR0175/ISO 15156 [8]: temperature $175^{\circ} \mathrm{C}$, deaerated $20 \% \mathrm{NaCl}$ solution, partial pressure of $\mathrm{CO}_{2}$ and $\mathrm{H}_{2} \mathrm{~S}-3.5 \mathrm{MPa}$. The pressure and temperature were monitored daily. Pressure stability maintained at $35 \mathrm{kPa}$ fluctuation. Temperature varied no more than $3^{\circ} \mathrm{C}$. Each test was performed on triplicate specimens.

The tendency of EP718 to crack in a hydrogen sulfide environment under stress was assessed in accordance with the requirements of the standard NACE TM 0177 [9]. The four-point bending method (FPB) was used as the method of testing for the studied alloy at $100 \%$ of the actual yield strength under test conditions. Specimens were stressed then isolated and placed in an autoclave for 90 days with total immersion in the liquid phase. After environmental exposure, all specimens were rinsed off with distilled water and leaned by polymer eraser. Examination of exposed SCC samples consisted of a visual examination at $10 \mathrm{x}$ magnification and metallographic examination by means of optical microscopy and scanning electron microscopy (SEM).

In order to determine the corrosion rate, the specimens were weighted before and after corrosion tests with definition of weight loss. Corrosion rate (CR) was determined by:

$$
C R=\left(m_{1}-m_{2}\right) / S \cdot t,
$$

where $\mathrm{m} 1$ is the mass of the specimens before tests $(\mathrm{g})$; $\mathrm{m}^{2}$ is the mass of the specimens after tests $(\mathrm{g}) ; \mathrm{S}$ is the specimen's surface $\left(\mathrm{m}^{2}\right)$; $\mathrm{t}$ is the time of tests (hours).

The microstructure was studied metallographically. Secondary phases were evaluated using scanning electron microscopy combined with an analysis of energy-dispersive X-ray spectrometry (EDS).

\section{Results and discussion}

\subsection{Assessing the rate of corrosion of EP718 samples at various heat treatment modes}

The results of the corrosion testing in an autoclave for determining the rate of corrosion are presented in Table 2.

The autoclave tests performed showed that the average corrosion rate of the samples at raised pressure and temperature is insignificant and equals less than $0.003 \mathrm{~g} / \mathrm{m}^{2}$.hour for all test samples.
Table 2. Results of autoclave gravimetric testing of alloy EP718 (conditions: $20 \% \mathrm{NaCl}, \mathrm{pH} 3.5,175^{\circ} \mathrm{C}, \mathrm{P}_{\mathrm{H} 2 \mathrm{~S}}=3.5 \mathrm{MPa}$, $\left.\mathrm{P}_{\mathrm{CO} 2}=3.5 \mathrm{MPa}\right)$.

\begin{tabular}{|c|c|c|c|}
\hline $\begin{array}{c}\text { Quenching } \\
\text { temperature, } \\
\text { C }\end{array}$ & $\begin{array}{c}\text { Holding } \\
\text { during } \\
\text { quenching, } \\
\text { hour }\end{array}$ & $\begin{array}{c}\text { Average } \\
\text { value of } \\
\text { mass loss, } g\end{array}$ & $\begin{array}{c}\text { Average value of } \\
\text { corrosion rate, } \\
\mathrm{g} / \mathrm{m}^{2} \cdot \mathrm{hour}\end{array}$ \\
\hline \multirow{2}{*}{980} & 1 & 0.0023 & $\begin{array}{c}0.0019 \\
\pm 0.0002\end{array}$ \\
\hline & 2 & 0.0025 & $\begin{array}{c}0.0020 \\
\pm 0.0005\end{array}$ \\
\hline \multirow{2}{*}{1030} & 1 & 0.0035 & $\begin{array}{c}0.0028 \\
\pm 0.0007\end{array}$ \\
\hline & 2 & 0.0036 & $\begin{array}{c}0.0029 \\
\pm 0.0008\end{array}$ \\
\hline \multirow{2}{*}{1080} & 1 & 0.0031 & $\begin{array}{c}0.0028 \\
\pm 0.0007\end{array}$ \\
\hline & 2 & 0.0031 & $\begin{array}{c}0.0026 \\
\pm 0.0008\end{array}$ \\
\hline \multirow{2}{*}{1130} & 1 & 0.0024 & $\begin{array}{c}0.0020 \\
\pm 0.0002\end{array}$ \\
\hline & 2 & 0.0022 & $\begin{array}{c}0.0018 \\
\pm 0.0006\end{array}$ \\
\hline
\end{tabular}

From the obtained experimental data, it can be seen that the corrosion rate increases with a raised quenching temperature up to a temperature of $1080^{\circ} \mathrm{C}$ and reduces at a temperature of $1130^{\circ} \mathrm{C}$. The biggest loss of weight was seen with samples after quenching at a temperature of 1030 and $1080^{\circ} \mathrm{C}$. The lowest loss of weight and corrosion rate correlates with a quenching temperature of 980 and $1130^{\circ} \mathrm{C}$ (Figure 1).

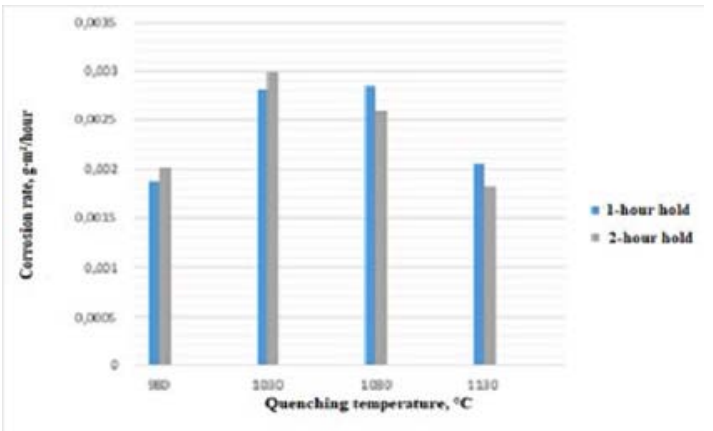

Fig. 1. Dependence of corrosion rate on quenching temperature.

All samples after testing have a dark coating of sulfur containing corrosion products on the surface (Figure 2). 


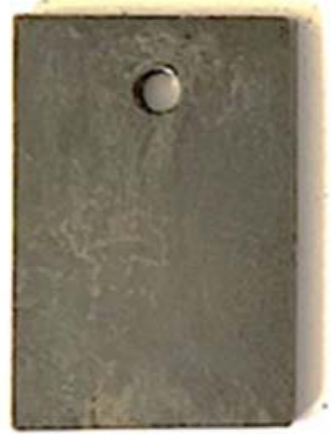

Fig. 2. View of sample after conducting autoclave testing in conditions approximate to real-life $\left(20 \% \mathrm{NaCl}, \mathrm{pH} 3.5,175^{\circ} \mathrm{C}\right.$, $\left.\mathrm{P}_{\mathrm{H} 2 \mathrm{~S}}=3.5 \mathrm{MPa}, \mathrm{P}_{\mathrm{CO} 2}=3.5 \mathrm{MPa}\right)$.

It can be noticed in Figure 2 that the sample lacks any visually detectable corrosion damage/pitting. However, when studying the surface of the samples using SEM, a number of localized damaged areas near the inclusions [12], clusters and grain boundaries were revealed. Examples of superficial damage to alloy EP718 after autoclave testing are presented in Figure 3.

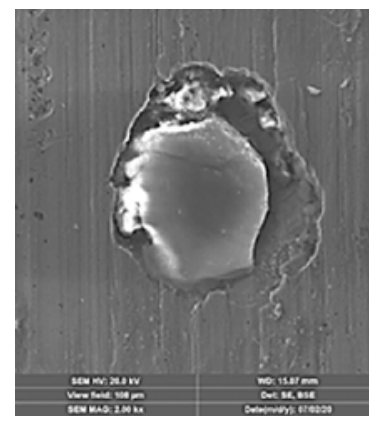

(a)

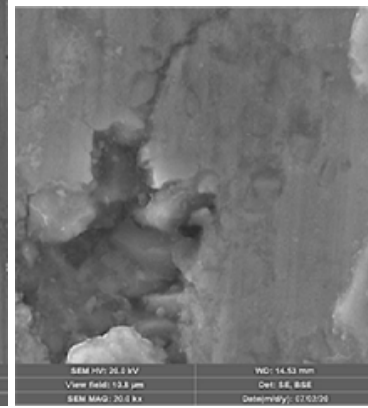

(b)

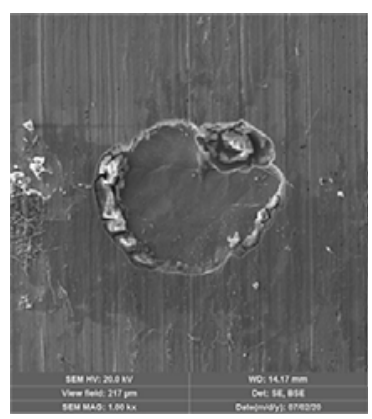

(c)

Fig. 3. Corrosion damage of samples of EP718 after autoclave testing: a) damage around individual inclusions, b) damage to clusters, c) damage along the grain boundaries.

\subsection{Assessing the resistance of EP 718 to sulfide stress corrosion cracking}

Test results of the samples after heat treatment for tendency of sulfide stress corrosion cracking over 1 month are presented in Table 3 .
Table 3. Results of autoclave testing of alloy EP718 for resistance to SSCC over 1 moth at a load of $100 \%$ of the actual yield point (conditions: $175^{\circ} \mathrm{C}, \mathrm{P}_{22 \mathrm{~S}}=3.5 \mathrm{MPa}$ and $\mathrm{P}_{\mathrm{CO} 2}=3.5$ $\mathrm{MPa})$.

\begin{tabular}{|c|c|c|c|c|c|}
\hline Condition & Sample & $\begin{array}{c}\text { Load, \% } \\
\boldsymbol{\sigma}_{\mathbf{T}}\end{array}$ & $\begin{array}{c}\text { Thickness, } \\
\mathbf{m m}\end{array}$ & Sag & Result \\
\hline $\begin{array}{c}\text { Quenching } \\
1080^{\circ} \mathrm{C} \\
\text { holding } 2 \\
\text { hours, oil } \\
\text { cooling }\end{array}$ & 2 & \multirow{2}{*}{100} & 2.85 & 2.72 & No res. \\
\cline { 2 - 4 } \cline { 4 - 6 } & 3 & & 3.05 & 2.53 & No res. \\
\hline
\end{tabular}

Results of assessing the tendency to crack in a hydrogen sulfide environment showed that all tested samples displayed sensitivity to corrosion cracking in an $\mathrm{H}_{2} \mathrm{~S}$ environment: at a load level of $100 \%$ of actual yield point, insignificant damage was discovered on the surface of the samples (Figure 4, a). A metallographic analysis (at x100 magnification) discovered cracks with a depth of $\approx 50-100 \mu \mathrm{m}$, which mostly developed along the grain boundaries, which is not a rejectable result according to NACE TM0177. However, it is evidence of a tendency to crack in test conditions (Figure 4, b).

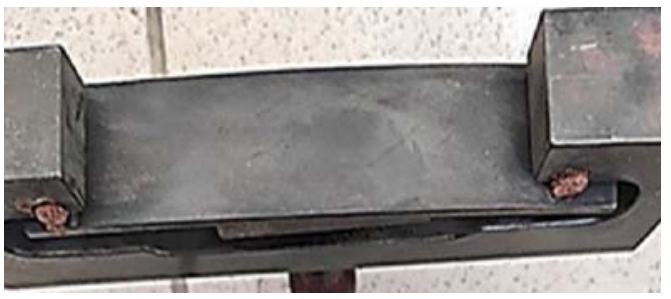

(a)

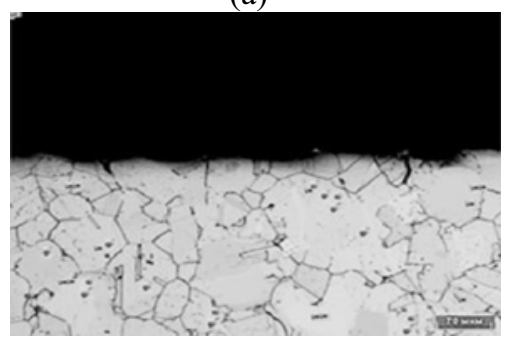

(b)

Fig. 4. External view of samples of alloy EP718 after testing for resistance to SSCC over 1 month at a load of $100 \%$ of the actual yield point (conditions: $175^{\circ} \mathrm{C}, \mathrm{P}_{\mathrm{H} 2 \mathrm{~S}}=3.5 \mathrm{MPa}$ and $\mathrm{P}_{\mathrm{CO} 2}$ $=3.5 \mathrm{MPa}$ ): a) general view of sample after testing $\mathrm{b}$ ) damage identified metallographically after testing.

\section{Conclusion}

Assessing the resistance of alloy EP718 after various types of heat treatment under corresponding conditions of operation: temperature $175^{\circ} \mathrm{C}$, partial pressure of hydrogen sulfide of $3.5 \mathrm{MPa}$ and carbon dioxide of 3.5

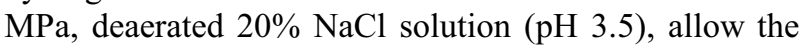
following conclusions to be made:

The results of the autoclave corrosion testing of samples of EP718 with a varying temperature and hold time during quenching showed that samples have an 
insignificant corrosion rate equaling less than 0.003 $\mathrm{g} / \mathrm{m}^{2}$.hour.

The heat treatment mode influences the corrosion rate. The corrosion rate increases with an increased quenching temperature up to a temperature of $1080^{\circ} \mathrm{C}$ and lowers at a temperature of $1130^{\circ} \mathrm{C}$.

The obtained results of corrosion testing showed that the samples of the domestic alloy EP718 displayed a slight tendency to corrosion stress cracking at a load level of $100 \%$ of actual yield point. Proof of this were the cracks identified on the surface of the samples after testing.

\section{References}

1. S. A. Mcoy, B. C. Puckett, E. L. Hibner, Corrotherm International Ltd, (2002)

2. J. J. Debarbadillo, S.K. Mannan, The Minerals, Metals \& Materials Society, (2010)

3. J. Xu, H. John, G. Wiese, X. Liu, TMS (The Minerals, Metals \& Materials Society, 2010)

4. S. Mannan, E. Hibner, B. Puckett, Special Metals Corporations Huntington

5. A. Davydov, E. Alekseeva, A. Gaev, Materials today: proceedings, (2020)

6. K.B. Konischev, A.A. Semenov, A.S. Chaban, N.A. Lobanova, R.V. Kashkovskiy, Scientific and technical collection Gas Science News, (2019)

7. A.M. Semenova, RosNITI, pt. 1, pp. 143-148, (2016)

8. NACE MR0175 NACE MR0175, NACE International, Houston, TX, (2015)

9. NACE Standard TM0177-2005, NACE International, Houston, TX

10. C.M. Viviane Smith, NACE International (2015)

11. A.A. Khar'kov; A.V. Shakhmatov; E.L. Gyulikhandanov; E.L. Alekseeva, Chemical and Petroleum Engineering, V. 54, № 9-10, pp. 771778. (2019)

12. A. Karasev, E. Alekseeva, A. Lukianov, P. Jönsson, E3S Web Conf, (2019)

13. H.S. Klapper; N.S. Zadorozne; R.B. Rebak, Acta Metall.Sinica, Vol.30, №4, pp. 296-305, (2017) 